\title{
Contradições da Assistência Social no governo "neodesenvolvimentista" e suas funcionalidades ao capital
}

\section{Contradictions of Social Assistance in "neodevelopment" government and its functionalities to capital}

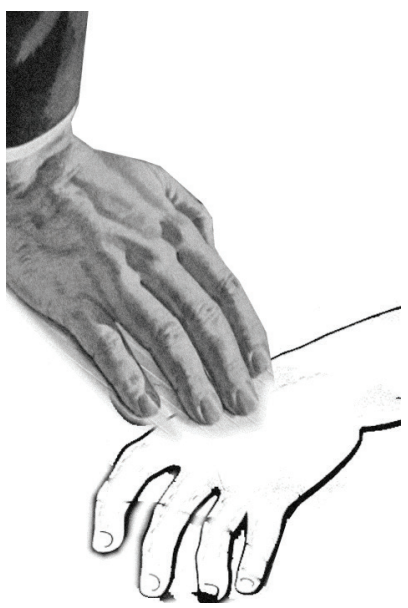

Sheyla Suely de Souza Silva*

Resumo: É na particularidade da inserção da economia brasileira na totalidade do capital que se explicitam as funcionalidades da política de Assistência Social às estratégias "neodesenvolvimentistas" de crescimento econômico e justiça social. Convertendo seus usuários trabalhadores apenas em "pobres", a Assistência Social brasileira assume um novo papel, o qual permite, em última análise, salvaguardar a riqueza produzida no país do conflito pela sua repartição e transferi-la para a expansão do capital internacional.

Palavras-chave: Neoliberalismo. Neodesenvolvimentismo. Social-liberalismo. Proteção social. Assistência Social.

\begin{abstract}
The peculiarity of the insertion of the Brazilian economy in the entirety of the capital show the Social Assistance policy functionalities related to the "neodevelopmentalist" strategies of economic growth and social justice. Converting its user-workers into only "very poor people", the Brazilian Social Assistance takes on a new role which leads to the protection of the country-produced wealth from the conflict over its distribution and to its transfer to the expansion of the international capital.
\end{abstract}

Keywords: Neoliberalism. Neodevelopmentalism. Social-liberalism. Social protection. Social Assistance.

* Doutora em Serviço Social pela Universidade Federal de Pernambuco, professora do Departamento de Serviço Social da Universidade Estadual da Paraíba - Campina Grande/PB, Brasil.

E-mail: sheylasuelyss@hotmail.com. 


\section{Introdução}

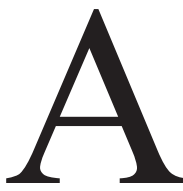

Assistência Social brasileira registra avanços jurídico-normativos; centralidade na proteção social, notoriedade nacional e internacional e integra um novo modelo de governo, "neodesenvolvimentista". Partindo do pressuposto de que todo avanço da política social condensa respostas às demandas do trabalho e funcionalidades à acumulação capitalista, analisamos, na contraface desses recentes avanços, as funcionalidades dessa política à atual expansão do capital.

Nossa análise, pautada no recurso heurístico da totalidade, evidencia que as atuais contribuições da política de Assistência Social brasileira à estratégia de crescimento econômico intermedeiam as dinâmicas de transnacionalização e financeirização e de superexploração do trabalho e, por outro lado, no que toca à face da justiça social do "neodesenvolvimentismo", o atual modelo dessa política (re)naturaliza a questão social e promove ações focalizadas, as quais revertem estatísticas de desigualdade social, sem promoverem redistribuição de riqueza e mantendo os custos de reprodução da superpopulação relativa no âmbito do trabalho.

Nossa tese é de que o atual modelo da política de Assistência Social brasileira dá suporte à superexploração do trabalho e equaliza a pobreza entre os próprios trabalhadores, para resguardar a riqueza produzida no país do conflito sobre a sua repartição e transferi-la para a expansão do capital, em escala internacional.

\section{A atual reestruturação do capital e suas inflexões sobre o trabalho, a questão social e a proteção social}

O sistema capitalista tem uma ineliminável capacidade de ampliar a pobreza no seio mesmo de seus avanços produtivos, como decorrência da produção social de uma riqueza apropriada de forma crescentemente concentrada, sob os desígnios da exploração do trabalho. Essa lei geral da acumulação capitalista é a determinação fundante da questão social e põe em confronto as duas classes fundamentais do capital. É na dinâmica desse confronto entre o capital e o trabalho que avançam ou refluem os diferentes modelos de proteção social. Neste sentido 
a análise da questão social é indissociável das configurações assumidas pelo trabalho e encontra-se necessariamente situada em uma arena de disputas entre projetos societários, informados por distintos interesses de classe, acerca de concepções e propostas para a condução das políticas econômicas e sociais. (Iamamoto, 2001, p. 10)

É, pois, nessa arena de disputas que podemos compreender a generalização das políticas sociais no contexto da onda longa expansiva do capital em sua fase fordista e a atual reversão deste modelo. Nos termos de Netto (1995, p. 70), o arranjo sociopolítico do Welfare State constitui uma possibilidade da ordem do capital que, pela lógica intrínseca desta última, converte-se agora num limite que ela deve franquear para reproduzir-se enquanto tal.

A rigidez fordista-keynesiana confronta-se com o novo estágio das forças produtivas do capital em sua fase de mundialização e impacta (1) na expansão internacional do modelo de flexibilização; (2) na emergência do neoliberalismo e (3) na contrarreforma do Estado, em especial nos termos universalistas em que foi consagrado como Estado de bem-estar social. Uma breve apreensão desses três movimentos que compõem as atuais transformações societárias é imprescindível à compreensão das funcionalidades da Política de Assistência Social brasileira à expansão do capital.

A mundialização vem sendo marcada como um regime de acumulação, no qual o novo estágio do imperialismo atua por meio da dominação do capital financeiro, em estreita articulação com as empresas transnacionais ${ }^{1}$ (Chesnais, 1996). Uma vez que a predominância do capital financeiro não substitui a esfera da produção como momento da criação de valor, o capital monetário, afirma Fontes (2010), precisa expandir relações sociais capitalistas de extração de mais-valor.

Assim, a lógica financeira pressiona para uma superexploração do trabalho, visando atender objetivos paradoxais. De um lado, resulta da maior aplicação de capitais na esfera especulativa, em detrimento produtiva, que, então, busca operar com menores custos, reduzindo gastos com o fator trabalho. ${ }^{2}$ Por outro lado, é uma

1. As empresas tipicamente industriais passam a conciliar suas atividades produtivas com as especulações financeiras (Harvey, 1994), e esse predomínio financeiro é acompanhado de dois mitos: o de que o lucro é produzido em nível intelectual da atividade de gestão do capital monetário e, decorrente desse primeiro, o mito de que o trabalho vivo não teria mais função na vida social (Fontes, 2010).

2. Nos termos de Alves (1999), nesse predomínio da financeirização, o processo de valorização é impulsionado na perspectiva da redução do trabalho vivo, para uma maior rentabilidade acionária. 
resposta à tentativa de reduzir a não correspondência entre o capital especulativo e a riqueza real, tendo a redução de custos com o fator trabalho também como seu pressuposto. A superexploração é, pois, um pressuposto tanto da financeirização, quanto da transnacionalização e se objetiva, historicamente, na transição para o modelo de "acumulação flexível".

Antunes (2007) descreve como principais elementos dessa reestruturação a reorganização sociotécnica da produção; a intensificação da jornada de trabalho, a subcontratação; a informalização e uma busca por uma mão de obra pouco qualificada, desfordizada e dessindicalizada, que, pressionada pela situação de mão de obra excedente, se submete a relações de trabalho altamente precarizadas.

Na conjuntura da da financeirização do capital, a reestruturação impõe, a um só tempo, a necessidade e a possibilidade de conciliar usos mais intensivos e extensivos da força de trabalho, ${ }^{3}$ e as novas estruturações do trabalho dissimulam uma realidade que reatualiza formas pretéritas de exploração, as quais rompem as conquistas seculares alcançadas no âmbito do conflito capital versus trabalho, exatamente para gerar um processo de "subproletarização tardia":

[...] o subproletariado tardio é [...] um "equivalente contemporâneo do proletariado sem direitos, oprimido e empobrecido" (o que Gorz denomina, por exemplo, "proletariado pós-industrial", é constituído não apenas pela subproletarização tardia, mas pelos desempregados estruturais)", sendo ambos adequados à lógica contemporânea da acumulação flexível. (Alves, 1999, p.152)

As atuais relações flexíveis de trabalho estabelecem uma nova relação, orgânica e reacionária, entre a expansão do capital e a espoliação do trabalho, que assimila novas e pretéritas formas de exploração, cuja inusitada conciliação caracteriza o fenômeno da superexploração e permite, também, o desvencilhamento de custos de reprodução da força de trabalho e um mascaramento da real dimensão da superpopulação relativa que vem sendo produzida crescentemente.

3. A derrocada do socialismo real e a reincorporação da União Soviética e da China como elementos do sistema capitalista mundial adensam sobremaneira essa conjuntura favorável à maior exploração e controle do trabalho pelo capital, uma vez que, assim, são execrados "quaisquer resquícios de modelos de sociedade alternativos ao capitalismo [sejam eles reais ou utópicos] e submetendo todo o globo à lógica, aos interesses e às imposições discricionárias do capital em sua nova fase imperialista" (Silva et al., 2010, p.182). 
A atual reestruturação produtiva - ao privilegiar formas de contratação do trabalho externalizadas das empresas capitalistas e assentadas no fornecimento de mercadorias e serviços - expressa a ofensiva do capital aos mais elementares direitos do trabalho: a jornada normal de trabalho e o salário necessário à reprodução do trabalhador e sua família, nas condições médias de vivência da classe trabalhadora, liberando as grandes empresas de responsabilidades e custos com encargos sociais, trabalhistas e fiscais, e mascara a amplitude da superpopulação relativa, sem amputar-lhe o papel de contribuir para a acumulação do capital. ${ }^{4}$

Enfim, as atuais transformações no mundo do trabalho tratam não de opções do trabalho, nem de resultados insatisfatórios de políticas ou governos mal administrados, mas de determinações imanentes à atual dinâmica de restauração do capital, as quais impactam nos atuais modelos de proteção social.

\subsection{As inflexões da atual reestruturação na (des)proteção social}

Esgotada a eficácia anticíclica do modelo fordista-keynesiano e substituídas as relações fordistas por padrões "flexíveis" de trabalho, produção e acumulação, explicita-se a demanda por um modelo de regulação distinto do keynesiano. Emerge o neoliberalismo e suas imposições às economias periféricas, sob a batuta das agências internacionais de crédito - Fundo Monetário Internacional e Banco

4. Rompida a relação entre pagamento do trabalho por tempo e a jornada normal de trabalho quando o capitalista paga o trabalhador por "horas avulsas", desconexas da sua relação com a jornada normal de trabalho - rompe-se, também, a conexão entre trabalho pago, trabalho não pago e reprodução do trabalhador, a qual serve de base para calcular a unidade de medida do preço do trabalho de forma que garanta a sobrevivência do trabalhador. O pagamento do salário por peça, serviço ou horas avulsas promove um prolongamento voluntário da jornada de trabalho, o rebaixamento do preço do trabalho e uma maior extração de mais-valia absoluta. Hoje, no duplo movimento entre o centro do sistema produtivo interno à empresa e o espaço externalizado de produção, amplas massas de trabalhadores desempregados passam a compor a superpopulação relativa estagnada e "[...] sua condição de vida cai abaixo do nível normal médio da classe trabalhadora e, exatamente isso faz dela uma base ampla para certos ramos de exploração do capital" (Marx, 2002a). Esta base, caracterizada como um "subproletariado tardio", oferta ao capital trabalho plasmado convertido na aparência de mercadorias (Soares, 2008). É nessa conversão que se opera a ruptura da relação entre o salário por tempo de trabalho e a jornada normal de trabalho e que se dissimula a reatualização de formas pretéritas de exploração, destinadas à retomada da expansão do capital. 
Mundial. O processo de mundialização do capital, sob a hegemonia neoliberal, é marcado pela ruptura com a regulação keynesiana do Estado, tanto na perspectiva do pleno emprego, quanto dos direitos sociais.

O final do século passado e o início do novo milênio testemunharam, então, a irrupção de mobilizações contra a ofensiva neoliberal ${ }^{5}$ e conduziram o neoliberalismo a uma restauração de tipo "social-liberalista" que, sob o mote retórico da justiça social, incorpora um novo discurso, articulando o crescimento econômico à equidade, como ferramentas do enfrentamento da questão social globalizada (Castelo, 2008). Para Castelo (2008) e Lehr (2010), o social-liberalismo é a nova fase do neoliberalismo em seu processo de restauração.

Na proposta desse social-liberalismo, encampada pelas agências multilateriais, ${ }^{6}$ o Estado assume um papel central para o crescimento econômico e o desenvolvimento social, por meio da garantia de condições básicas para que todos possam usufruir de oportunidades no mercado. Eis os fundamentos que conciliam a promoção do mercado com a equidade, a qual, no caldo ideopolítico social-liberalista, tomada com o sentido de uma justiça social mediada pelo conceito de "inclusão social", focaliza suas ações na pobreza absoluta $^{7}$, excluindo qualquer debate ou intervenção nas desigualdades sociais.

O social-liberalismo é, pois, uma proposta de contrarreforma do Estado que, assimilada, no Brasil, pelo atual modelo da política de Assistência Social, visa fazer frente aos efeitos mais gritantes da liberalização dos mercados, exatamente para manter a trajetória concentradora do capital e suas consequentes desigualdades. É apenas no contexto dessas grandes transformações societárias que podemos apreender as funcionalidades da política de Assistência Social ao modelo brasileiro de governo "neodesenvolvimentista".

5. Castelo (2008) cita, como exemplos dessas irrupções, o Primeiro Encontro Intercontinental pela Humanidade e Contra o Neoliberalismo, realizado no México, em 1996; as mobilizações contra o Acordo Multilateral de Investimentos, desencadeadas entre os anos de 1997 e 1998, que conduziram ao cancelamento do acordo, em outubro de 1998; as mobilizações contra a Rodada do Milênio, em Seattle, Estados Unidos, em 1999; as diversas mobilizações contra o FMI, no início dos anos 2000, destacando-se as de Washington e de Praga.

6. O social-liberalismo inspira-se nas contribuições teóricas de um dos recentes presidentes do Banco Mundial, o economista premiado Nobel Amartya Kumar Sen, em especial na sua obra Desenvolvimento como liberdade (2000). Importante interpretação de suas propostas encontra-se em Mauriel (2008).

7. Tratando-se, então, dentro dos parâmetros da cidadania liberal-burguesa, de um retorno do princípio da justiça social à sua ênfase compensatória. 


\section{0 "neodesenvolvimentismo" brasileiro: sua proposta e sua não concreção}

Tem sido recorrente a interpretação de que, no Brasil, a partir do segundo mandato do presidente Lula, emerge um novo modelo de governo, denominado "neodesenvolvimentista". Castelo (2009) afirma que, para os seus proponentes, embora esse modelo tenha suas raízes fincadas na matriz nacional-desenvolvimentista, ${ }^{8}$ deve hoje adensar um "sentido conceitual inovador", adequado às novas configurações do capitalismo contemporâneo, daí o prévio adjetivo de "neo" ou "novo" desenvolvimentismo.

Na concepção de Sicsú (2008), esse modelo deve promover crescimento com industrialização, por meio dos seguintes fundamentos: uma política monetária lastreada por juros baixos; uma política cambial que administre uma taxa de câmbio competitiva para a exportação de manufaturados e com regulação do fluxo de capitais financeiros; uma política fiscal que cumpra o papel de controlar gastos públicos com o objetivo de manter o pleno emprego, melhorar as condições de vida da população e realizar uma arrecadação progressiva.

Para Pochmann (2010), são pressupostos desse "social-desenvolvimentismo" um novo caminho que inclua justamente todos os brasileiros e que seja compatível com o avanço tecnológico da nação e a sustentabilidade ambiental. Sua concreção requer a "refundação do Estado", através da constituição de novas institucionalidades na sua relação com o mercado, tendo em vista garantir a inovação, por meio da "concorrência combinada entre empreendedores e da maior regulação das grandes corporações empresariais" (p. 179) e a ampliação do fundo público, por via de uma maior tributação das grandes fortunas e propriedade intelectual e do avanço para um sistema tributário progressivo.

$\mathrm{Na}$ análise de Sallun Jr. (2009), o modelo de governo do segundo mandato Lula se diferencia do neoliberalismo porque propõe um Estado forte, que intervém em favor da economia; e se diferencia, também, do nacional-desenvolvimentismo porque não almeja o mercado interno, mas, constitui-se uma economia competitiva no plano internacional, por meio da atração das empresas transnacionais, do estímulo às inovações tecnológicas e dos investimentos em infraestrutura. O papel

8. O modelo nacional-desenvolvimentista foi proposto entre as décadas de 1940 e 1970 e suplantado pela ofensiva neoliberal a partir dos anos 1980 . 
do Estado "neodesenvolvimentista" é regular e impulsionar de forma eficiente o crescimento econômico com inclusão social.

Na crítica de Castelo (2007 e 2009), a corrente "neodesenvolvimentista" nasceu na esteira da tradição nacional-desenvolvimentista que, malograda, foi suplantada pelo neoliberalismo e, assim, a emergência do atual modelo de governo se dá em meio a um quadro social adverso aos seus objetivos políticos, cobrando-lhe, constantemente, a prestar contas ao nacional-desenvolvimentismo - do qual é legatário - e enfrentar o neoliberalismo - com o qual é interlocutor. $\mathrm{O}$ autor adverte que o termo "novo desenvolvimentismo" remonta à produção teórica de Luiz Carlos Bresser Pereira, passando a compartilhar com os teóricos da atual proposta vários ideais, no sentido de torná-lo adequado às configurações do capitalismo contemporâneo.

Gonçalves (2011), outro crítico desse modelo "neodesenvolvimentista", atribui ao governo Lula a responsabilidade de ter implementado um "nacional-desenvolvimentismo às avessas", tendo em vista que operou, na esfera comercial, uma desindustrialização, dessubstituição de importações, reprimarização e perda de competitividade internacional; na esfera tecnológica, uma maior dependência aos setores externos; na esfera produtiva, uma desnacionalização e maior concentração do capital e, na financeira, teria estimulado um passivo externo crescente e a dominação financeira.

Acerca do "neodesenvolvimentismo" brasileiro, é necessário desprender nossas críticas em duas direções: primeiro à sua proposta original, encampada por ideólogos como Sicsú e Pochmann e, segundo, ao modelo que efetivamente se concretiza nas ações de governo. Em ambas as direções, esse modelo é caracterizado pelo que Castelo (2009) denominou como uma "terceira via" que, inspirada na ideologia social-liberalista das agências multilaterais, propõe conciliar, ao conjunto de medidas macroeconômicas acima descritas, um conjunto de medidas sociais que atuem sobre a questão social e promovam a equidade e a justiça social. ${ }^{9}$ Esta terceira via encontra amplo respaldo no atual modelo da política de Assistência Social brasileira.

9. Seja na sua proposta original, seja na sua concreção como modelo de governo efetivamente implementado, a ambiguidade central do "neodesenvolvimentismo" é, a nosso ver, a sua conivência antagônica com a liberalização dos mercados e a especulação financeira, as quais confrontam tanto as propostas de medidas macroeconômicas que promovam o desenvolvimento nacional, quanto aquelas que promovam a justiça social. Ao se confrontar com as inflexões objetivas da ofensiva do capital, qualquer desenvolvimento nacional é confinado a limites que não constranjam a reposição do ciclo de subdesenvolvimento como um fenômeno imanente à lógica da globalização capitalista. As escolhas tomadas frente a esses conflitos anta- 


\section{Interlocuções da política de Assistência Social com 0 "neodesenvolvimentismo" brasileiro}

Um dos avanços que se registram no governo "neodesenvolvimentista" é a expansão da política de Assistência Social e sua regulamentação, na perspectiva de instituir o Sistema Único de Assistência Social (Suas). Partindo daquele pressuposto já anunciado de que toda política social atende a demandas do trabalho, mas é, também, funcional às requisições da expansão do capital, apreendemos, na contraface dos recentes avanços da política de Assistência Social, as suas funcionalidades às requisições da dinâmica de expansão do capital no Brasil.

O próprio marco regulatório recente da Assistência Social — não sendo imune à dinâmica conflitiva capital/trabalho - incorpora conceitos sociais-liberalistas, os quais visam à (re)naturalização da questão social, despolitizando-a, para blindá-la de qualquer reflexão que permita o tensionamento de suas causas fundantes: a expropriação e a exploração dos trabalhadores.

Neste sentido, Castelo (2009) questiona a assunção do conceito de equidade na intervenção "neodesenvolvimentista", posto que, herdado da tradição liberal clássica, abraçado pelo Banco Mundial (BM) e mediado pela perspectiva da inclusão, permite o corte da focalização na extrema pobreza. ${ }^{10} \mathrm{Na}$ mesma direção, a propositura do conceito de vulnerabilidade social remete à estratégia da responsabilização dos indivíduos. Para Mendonça (2010), essa reconceituação é oportuna no sentido de propor que o próprio indivíduo pobre construa alternativas para a superação de sua condição, correspondendo às orientações sociais-liberalistas do Banco Mundial. ${ }^{11}$

gônicos (macroeconômicos e político-sociais) expressam, "factualmente", o modelo e os beneficiários do desenvolvimento empreendido.

10. Encontra-se na teoria rawlsiana da "justiça como equidade" uma matriz de pensamento que orienta esse retorno (liberal) de uma ênfase da justiça social pautada no princípio da redistribuição para uma ênfase compensatória. O novo marco regulatório da Assistência Social brasileira se alinha a essa concepção, quando, por exemplo, propõe que a "visão social inovadora" da política paute-se na "dimensão ética de incluir os “invisíveis"” (Brasil/MDS/SNAS, 2004, p. 15).

11. A impregnação desse marco social-liberalista revela-se, por exemplo, na proposta de que a visão social inovadora da Assistência Social identifique e potencialize "os requisitos sociais circundantes do indivíduo e dele em sua família" como "determinantes para a sua proteção e autonomia", confrontando "leituras macrossociais" com "leituras microssociais" que potencializem as possibilidades e capacidades dos próprios 
Se, no caráter estrito da recente regulamentação da Assistência Social brasileira, flagramos a sua impregnação pelo caldo político-ideológico social-liberalista, na perspectiva da inserção do país na totalidade do capital, a centralidade da Assistência Social é anunciada como uma das principais ações que comporiam o novo modelo de governo, cujo fundamento é a inédita articulação do binômio do crescimento econômico com a redução da pobreza. A adoção desse binômio é, a nosso ver, também um substrato da apropriação que esse modelo "neodesenvolvimentista" faz da matriz social-liberalista, sendo, inclusive, cunhado por alguns autores de "modelo social-desenvolvimentista" (Pochman, 2010) e que segue as recomendações das agências multilaterais. ${ }^{12}$

No caso do crescimento econômico, as principais estratégias "neodesenvolvimentistas" privilegiam a exportação de commodities e a atração das grandes empresas transnacionais e do capital financeiro, por meio dos investimentos estrangeiros diretos (IEDs). Na outra ponta, o desenvolvimento social seria alcançado por meio do fortalecimento dos programas sociais, com destaque para os programas de transferência de renda da política de Assistência Social.

No tocante ao crescimento econômico, o Brasil retoma a velha opção de crescimento pela via das exportações de commodities, com base nas "vantagens comparativas" e marcada por baixa reinversão tecnológica, reprimarização da economia e superexploração do trabalho, a qual é típica da produtividade desse setor primário. No que diz respeito à atração de capitais, o estoque total dos IEDs no país atingiu 30,8\% do PIB e aqueles relativos à participação no capital cresceram $256 \%$, entre 2005 e 2010 , atingindo um montante equivalente a $27 \%$ do PIB (Banco Central do Brasil, 2011).

Segundo o Relatório de Inflação do Banco Central do Brasil (2008), a remessa de lucros e dividendos ao exterior acompanhou o crescimento de IEDs, tendo montantes comumente superiores aos dos investimentos, no período 2001-2007. ${ }^{13}$

beneficiários, para os quais o direito à Seguridade Social deve ter o duplo efeito de "suprir um recebimento" e desenvolver suas "capacidades para maior autonomia" (Brasil/MDS/SNAS, 2004, p. 15-16; grifos nossos).

12. O social-liberalismo parece-nos, pois, a matriz político-ideológica que sustenta o modelo "neodesenvolvimentista", o qual se apoia na conciliação entre crescimento econômico e equidade. Observe-se, por exemplo, que o governo "neodesenvolvimentista" assume como meta da "justiça social" exatamente aquilo que o Banco Mundial assume como sua principal missão: a redução da pobreza absoluta (ver Banco Mundial, 2006).

13. Apenas nos segundo e terceiro triênios de 2004; terceiro e quarto triênios de 2006 e primeiro triênio de 2007 o montante das remessas foi igual ou inferior aos estoques de IEDs - participação no capital. Em todos os demais triênios desses sete anos (2001-2007), as remessas foram superiores. 
Enfim, essas duas principais estratégias de crescimento econômico e de inserção no sistema internacional reincidem na condição de dependência e heteronomia e, em verdade, obliteram a proposta de desenvolvimento. ${ }^{14}$

O "neodesenvolvimento" brasileiro promove um crescimento econômico cujas maiores fatias são apropriadas pelas transnacionais e, em verdade, dissimula o fenômeno do novo imperialismo, remetendo às sedes das empresas transnacionalizadas as maiores fatias do crescimento interno, alcançado pela via da dilapidação dos recursos naturais e da exploração do trabalho precário ${ }^{15}$, sob um dissimulado "sucesso" da justiça social, expressa em termos de aumento de postos de trabalho e redução da desigualdade de renda, também entre o próprio trabalho.

Os organismos e as estatísticas oficiais afirmam que o Brasil gerou milhões de postos de trabalho, fez emergir uma nova classe média e criou uma sólida economia interna, resistente às crises internacionais. A reversão positiva de indicadores sociais compõe o principal sustentáculo ideopolítico para o colaboracionismo em torno do modelo "neodesenvolvimentista" e, com ele, da apropriação que o grande capital internacional opera sobre o crescimento econômico (aparentemente) brasileiro, e não é pequeno o papel da Assistência Social nesse processo.

Ainda quanto às transformações no âmbito do trabalho, cabe ressaltar, a partir dos dados do Ipea (ago. 2011, fev. 2012) e da Anfip (2011), que o saldo positivo do trabalho, desde 1995, se deu sempre nas faixas de rendimento mais baixas, com expressiva predominância de postos com rendimentos de até 1,5 salário, e esses saldos positivos se deram em virtude da eliminação de postos de trabalho em faixas salariais maiores. Em verdade, a geração de postos de trabalho é dada em função e à custa da degradação da renda do trabalho em seu conjunto. ${ }^{16}$

14. Explicitam-se, assim, os motivos pelos quais optamos por nos referir aos termos relativos ao "neodesenvolvimentismo" sempre marcados pelo recurso das "aspas", posto tratar-se, a nosso ver, de termos eminentemente retóricos que, em verdade, operam no plano real exatamente o inverso daquilo a que se propõem no discurso ideológico de seus proponentes e executores.

15. Várias denúncias derivam desse colaboracionismo do governo "neodesenvolvimentista" à ofensiva novoimperialista; dentre os quais destacamos, por exemplo, a estrangeirização do latifúndio e o baixo investimento nas inovações tecnológicas (Silva, 2012).

16. Ao apontar o saldo positivo entre contratações e demissões, não podemos ignorar que não se trata de postos de trabalho idênticos. Na verdade, do total de postos criados em 2009 , cerca de $36 \%$ operaram uma migração de trabalhadores com maiores rendimentos para faixas de rendimentos inferiores a dois salários mínimos. Em 2010, essa migração foi de mais 12,95\%. Segundo o Ipea (ago. 2011), o primeiro decênio dos anos 2000 registrou a maior expansão quantitativa de ocupações dos últimos quarenta anos, e 95\% das vagas 
O fato é que, no atual momento histórico, o capital em crise distancia-se em marcha acelerada das prerrogativas fordistas-keynesianas do pleno emprego e do bem-estar e opta (por absoluta necessidade estrutural) por empregar mão de obra precária e descartável, encontrando no Brasil um manancial na oferta desse perfil de trabalho e amplos subsídios dos governos a essas subcontratações. Parte desses subsídios apresenta-se na forma dos programas de transferência de renda. Segundo a Anfip (2011), a importância desses programas na conjugação das estatísticas positivas do trabalho não foi pequena e

a Seguridade cumpriu um papel importante ao financiar as políticas de reajustes reais para o salário mínimo, de programas de benefícios assistenciais de prestação continuada, do Bolsa Família e de outros benefícios de natureza assistencial. (Anfip, 2011, p. 10; grifos nossos)

Vejamos, então melhor, como a preeminência dos programas de transferência de renda incide sobre o crescimento econômico e a justiça social do governo "neodesenvolvimentista".

\section{Funcionalidades da preeminência da transferência de renda à expansão do capital no Brasil}

Na política de Assistência Social há uma preeminência de programas de transferência de renda, em detrimento da ampliação dos serviços socioassistenciais, comprometendo uma integração do Sistema Único de Assistência Social (Suas) que garanta o acesso por todos aqueles que dele necessitarem, para além da condição da pobreza extrema. A partir de dados da Anfip (2011), observa-se que o montante dos valores liquidados com o Benefício de Prestação Continuada (BPC) e o Programa Bolsa Família (PBF) evoluiu 136,46\% ${ }^{17}$ entre os anos de 2005 a 2010; mas

abertas foram com remuneração mensal de até 1,5 salário mínimo. Esse contingente de remuneração aproxima-se de quase $59 \%$ de todos os postos de trabalho do país.

17. Cabe ressaltar que essas são as duas principais estratégias de transferência de renda no âmbito da Assistência Social, porém, não são exclusivas, pois, outros programas - a exemplo do Programa de Erradicação do Trabalho Infantil (Peti) e do Pró Jovem — também realizam transferências de renda, ainda que com valores, montantes e beneficiários em números expressivamente menores; além dos repasses da Renda 
a execução dos montantes referentes aos serviços e aos programas da Assistência Social teve evolução significativamente menor, no mesmo período de referência.

O MDS (2010) relata que, incluindo o BPC e o PBF, a evolução dos recursos da Assistência Social na União teve um incremento real de 255,4\%; mas, excluídos esses programas, a expansão dos serviços socioassistenciais foi de R $\$ 2$ bilhões, em 2004, para R \$ 2,7 bilhões, em 2009, representando um incremento percentual de apenas $35 \%$ em cinco anos. Esses dados evidenciam a prevalência da transferência de renda como estratégia central da proteção social brasileira, no governo "neodesenvolvimentista", ${ }^{18}$ restando-nos questionar a funcionalidade dessa prevalência para a expansão do capital.

O Ipea vem divulgando sucessivas quedas no grau de desigualdade e de concentração dos rendimentos do trabalho no país desde 2002, capturadas pelo índice de Gini. Em agosto de 2009, o Instituto divulgou uma redução de 9,5\% entre dezembro de $2002(0,545)$ e junho de 2009 (0,493). No mesmo documento, o Ipea (ago. 2009, p. 3) observa que:

a renda capturada pela PME/IBGE expressa fundamentalmente os rendimentos do trabalho, observa-se que a queda do índice de Gini pode estar relacionada tanto à perda do valor real das maiores rendas do trabalho como à proteção do conjunto dos rendimentos na base da pirâmide ocupacional. (Grifos nossos)

Além da valorização do salário mínimo na base da pirâmide com uma deterioração do valor real das maiores rendas do trabalho no seu ápice, a dinâmica de demissão de trabalhadores nas faixas salariais mais altas com admissões exclusivamente em faixas salariais inferiores também contribuiu para a diminuição do índice de Gini. ${ }^{19}$ Dedecca et al. (2008) sinalizam que a redução desse índice está

Mensal Vitalícia (RMV) aos beneficiários remanescentes de um direito adquirido antes da Constituição Federal de 1988, cujo montante de recursos é menor e decrescente, devendo extinguir-se.

18. Enquanto há um expressivo acesso à transferência de renda pelos idosos, pessoas com deficiência e famílias em situação de pobreza extrema, sendo muitos desses acessos assentados na provisoriedade de um "programa de governo", esses mesmos usuários não encontram, na maioria dos municípios brasileiros, a disponibilidade de serviços socioassistenciais de atenção e acolhimento ao idoso; de habilitação e reabilitação da pessoa com deficiência, de acolhimento e proteção à mulher vítima de violência etc. (IBGE, 2010), esvaziando a PAS da concretude, previsibilidade, integralidade e continuidade que lhe são devidas, posto seu caráter de política pública.

19. Importante análise de Dedecca et al. (2008) demonstra claramente as restrições da apropriação dos dados da PNAD pelo índice de Gini para a mensuração da desigualdade. Os dados do recente Comunicado 
"aderida", também, à evolução das distribuições da renda do trabalho e à renda oriunda da proteção social, donde destacam "o papel importante cumprido pelo programa $[\mathrm{PBF}]$ junto às famílias com maior carência de renda" (p. 12). Também o Ipea (fev. 2011) avalia que a atual abrangência do PBF e do BPC tem papel estratégico para "alavancar a economia".

Em síntese, o Instituto demonstra que os gastos das políticas sociais se convertem, também, em benefícios de caráter estritamente econômico, como o crescimento da renda das famílias e do PIB, para os quais esses gastos têm efeito multiplicador maior que o efeito do investimento, o da exportação de commodities agrícolas ou o efeito do pagamento de juros, posto que gastos de benefícios assistenciais (BPC e PBF) e previdenciários alcançam os mais pobres e a classe média, cujos consumos dirigem-se ao mercado interno. Também no tocante ao índice de Gini, o Instituto demonstra que "gastos incrementais no BPC e PBF são claramente os que mais contribuem para a queda da desigualdade, corroborando o 'papel virtuoso do gasto social e, mais especificamente, das transferências de renda direcionadas aos mais pobres"”.

Os dados evidenciam que a Assistência Social vem respondendo, em boa medida, à face da justiça social "neodesenvolvimentista" — concebida pelo veio da focalização na extrema pobreza e expressa na reversão estatística dos índices de pobreza e de desigualdade (no âmbito dos rendimentos do trabalho) - enquanto também contribui significativa e monetariamente para a outra face desse modelo, que é o crescimento econômico, ao compor o que Sicsú (2008, p. 19, grifos nossos) propõe como "a arte da política fiscal de gastos que não aumentam gastos"; elevar o efeito multiplicador dos gastos do governo e, assim, "trocando beneficiário 'ricos' por "pobres"', gerar crescimento. ${ }^{20}$

n. 134 do Ipea (fev. 2012) revelam que, entre 1995 e 2002, houve uma redução de 11,8\% na fatia da participação do trabalho na renda nacional, que variou de 48\% (em 1995) para 42,4\% (em 2002) e, apesar dos recentes (e comemorados) saldos positivos do crescimento econômico brasileiro, entre 2003 e 2009, a recuperação da participação dos rendimentos do trabalho foi de apenas 2,5\%, alcançando 43,4\% em 2009 e permanecendo 9,6\% abaixo do percentual de 1995.

20. Somente o Programa Bolsa Família atende algo em torno de 50 milhões de brasileiros, ou seja, pouco mais de um quarto da população do país e, ao baixo custo de $0,4 \%$ do Produto Interno Bruto (PIB) (Falcão, 2011), alivia a pobreza, reverte as suas estatísticas e as da desigualdade, inflexiona positivamente as estatísticas da Saúde e da Educação, devido às condicionalidades do programa, e incrementa o circuito do consumo e da economia, aumentando a capacidade de consumo das famílias beneficiárias e o PIB. 


\section{Algumas notas conclusivas acerca da funcionalidade da política de Assistência Social brasileira à expansão do capital}

Nossa análise corrobora o pressuposto de que a contrapartida da transferência de renda às classes trabalhadoras é favorável aos trabalhadores, principalmente em termos de um complemento à escassez de renda oriunda do trabalho precário e, mais ainda, é funcional ao capital, tanto ideopolítica, quanto economicamente.

$\mathrm{O}$ incremento desses programas à fatia do crescimento econômico brasileiro que escapa da apropriação do capital internacional e engrossa o PIB nacional não é pequeno, posto que são seus beneficiários quem consomem os produtos nacionais e quem movimentam as economias municipais, enquanto as velhas e novas "minorias privilegiadas e miméticas" (Furtado, 1974) continuam investindo no capital financeiro, consumindo importados e transferindo para as grandes empresas transnacionalizadas a riqueza nacional, pela via desse consumo, pela concessão do direito de exploração espoliativa de nossos recursos naturais, dentre os quais a força de trabalho e, ainda, pela via da mercantilização dos direitos do trabalho, como Previdência, Saúde e Educação.

Numa economia mundializada, em que as grandes empresas transnacionais remetem às suas matrizes as maiores fatias da riqueza produzida no país, o mínimo crescimento da participação do trabalho na renda nacional não reflete, em absoluto, maior participação na magnitude da riqueza total produzida, porque a maior parte dela foi exportada. Havemos, ainda, de descontar do aumento dessa participação a fatia da renda do trabalho que se converte no sustento da superpopulação relativa, o que toca, prinicipalmente, na questão dos montantes de recursos públicos destinados aos programas sociais.

Nesse sentido, lembremos que os atuais beneficiários dos programas de transferência de renda são, também, trabalhadores aptos, subocupados, com escassos rendimentos per capita familiar, ${ }^{21}$ remanescentes da superpopulação relativa ampliada pela ofensiva dos anos 1990. Através daquela ofensiva, o desemprego estrutural, a reversão de direitos sociais e trabalhistas e a privatização dos bens e serviços públicos; o aumento da dívida pública interna e externa; inflação, perdas

21. Couto (2011) refere que, segundo a última pesquisa feita pelo BPC, $47 \%$ dos usuários do Programa Bolsa Família têm trabalho com carteira assinada e cerca de $70 \%$ a $80 \%$ desses usuários encontram-se no setor informal. 
salariais e quebra dos laços de solidariedade e das estratégias e do poder de barganha dos trabalhadores etc., enfim, novos processos de "expropriações secundárias" (Fontes, 2010) forjaram, a ferro e fogo, o perfil adequado de trabalhadores para atender às atuais necessidades do capital de superexploração do trabalho.

Hoje, com amplo respaldo e incentivo de governo, esse "subproletariado tardio" é inserido em ações e programas que ampliam formas precárias de inserção ocupacional (empreendedorismos, pequenos negócios, economia solidária, produções familiares, novos arranjos produtivos locais etc.) e, assim, submetem-se de bom grado à autoexploração extensiva de sua força de trabalho, em favor da concessão de uma formidável quantidade de mais-valia absoluta ao capital, "plasmada" na forma aparente de serviços e mercadorias, isenta de custos sociais e trabalhistas e, na maioria das vezes, remunerada de forma desconexa da jornada normal de trabalho. ${ }^{22}$

Esse quadro consolida a inserção do Brasil na divisão internacional do trabalho como um ofertador de mão de obra barata, desqualificada e precária. E se esses trabalhadores, consequentemente, não obtêm renda suficiente para o seu sustento e o de suas famílias, podem recorrer aos programas sociais focalizados, cujos gastos os reintegram ao consumo, tanto em benefício de atender aos limites mínimos de sua reprodução humana, em nome de uma justiça social compensatória, quanto em benefício da "circularidade econômica" e da especulação financeira do capital sobre o fundo público, em proveito de sua expansão, sob o argumento do crescimento econômico e do desenvolvimento (aparentemente) nacional.

Eis, pois, as razões pelas quais o governo "neodesenvolvimentista" elege a Assistência Social como política pública central na proteção social e aos programas de transferência de renda aos mais pobres como principais estratégias dessa proteção. Assim, o modelo brasileiro de Seguridade Social devolve à esfera privada os direitos comuns de propriedade sobre o bem-estar que foram conquistados pela luta do trabalho, atendendo às requisições da acumulação espoliativa do capital, no seu novo estágio de imperialismo, como denuncia Harvey (2004) e, por outro lado, a Assistência Social brasileira, assentada na transferência de renda e financiada por um fundo público oriundo, prioritária e maciçamente, das contribuições sobre a

22. Esse processo de "subproletarização" do trabalho é, a nosso ver, expressão da acumulação espoliativa do capital em sua nova ofensiva imperialista. Apropriando-nos das reflexões de Harvey (2004), afirmamos que essa força de trabalho foi deliberada e intencionalmente convertida em "ativos desvalorizados", exatamente para ser apropriada em função da lucratividade e da expansão do capital. 
renda do próprio trabalho, se incumbe de assumir o ônus da promoção da justiça social proposta pelo governo "neodesenvolvimentista", arcando com os custos de manutenção da superpopulação relativa. ${ }^{23}$

Sob o novo receituário social-liberalista, a Assistência Social assume o papel de convencer homens e mulheres, saudáveis, aptos e ávidos por trabalho que, por um lado, o trabalho estável e protegido é um privilégio inatingível e, por outro, que, não integrando eles a classe dos produtores de riqueza, devem, então, eximirem-se do conflito pela sua devida repartição. Para tanto, essa política social pública descaracteriza seus usuários da condição de trabalhadores e os caracteriza, apenas, como extremamente pobres.

Essa equalização da pobreza entre os próprios trabalhadores, salvaguardando a riqueza do conflito pela sua repartição, é, no reverso contraditório dos atuais avanços da Assistência Social brasileira, a principal funcionalidade que se impõe a essa política social, para que atenda às requisições da expansão capitalista.

Recebido em 3/12/2012 - Aprovado em 10/12/2012

\section{Referências bibliográficas}

ALVES, G. Trabalho e mundialização do capital: a nova degradação do trabalho na era da globalização. 2. ed. Londrina: Práxis, 1999.

ANFIP. Associação Nacional dos Auditores Fiscais da Receita Federal do Brasil. Análise da Seguridade Social em 2010. Brasília: Anfip, 2011. Disponível em: <www.anfip.org.br>. Acesso em: 25 jun. 2011.

ANTUNES, R. Dimensões da precarização estrutural do trabalho. In: DRUCK, G.; THEBAUD-MONY, A. A perda da razão social do trabalho: terceirização e precarização. São Paulo: Boitempo, 2007.

BANCO CENTRAL DO BRASIL. Relatório de inflação, set. 2008. Disponível em: <http:// www.bcb.gov.br>. Acesso em: 23 jul. 2011.

23. Assim, como já anunciava Marx (2002a, p. 748), embora o pauperismo faça parte das despesas extras da produção capitalista, "o capital arranja sempre um meio de transferi-las para a classe trabalhadora e para a classe média inferior". 
BANCO CENTRAL DO BRASIL. Censo de capitais estrangeiros no país 2011 - ano-base 2010 resultados preliminares. Disponível em: <http://www.bcb.gov.br/?CENSO2010P $>$. Acesso em: 28 dez. 2011.

BANCO MUNDIAL. Relatório sobre o desenvolvimento mundial. Equidade e desenvolvimento. Visão geral. Washington, DC, 2006. Disponível em: <http://siteresources.worldbank. org/INTWDR2006/Resources/477383-1127230817535/0821364154.pdf>. Acesso em: 29 mar. 2012.

BRASIL/MDS/SNAS. Política Nacional de Assistência Social. Brasília: MDS, 2004.

CASTELO, R. Crescimento econômico e equidade social: o modelo novo-desenvolvimentista de intervenção sobre a "questão social". In: JORNADA INTERNACIONAL DE POLÍTICAS PÚBLICAS, 3., Anais... São Luís, Programa de Pós-Graduação em Políticas Públicas/UFMA, 2007.

O social-liberalismo e a globalização da "questão social". In: CONFERÊNCIA INTERNACIONAL "LA OBRA DE CARLOS MARX Y LOS DESAFIO DEL SIGLO XXI”, 4., Anais... Havana, Instituto de Filosofia de La Habana, 2008.

O novo-desenvolvimentismo e a decadência ideológica do estruturalismo latino-americano. Oikos. Rio de Janeiro, v. 8, n. 1, 2009.

CHESNAIS, F. A mundialização do capital. São Paulo: Xamã, 1996.

COUTO, B. R. Assistência Social em debate: direito ou assistencialização? (Mesa-redonda). In: CFESS. O trabalho do assistente social no Suas/Seminário Nacional. Brasília: CFESS, 2011.

DEDECCA et al. A queda recente da desigualdade: relevância e limites. In: ENCONTRO NACIONAL DE ECONOMIA, 36., Anais... Salvador, Associação Nacional dos Centros de Pós-Graduação em Economia (Anpec), 2008. Disponível em: <http://www.anpec.org.br/ encontro2008/artigos/200807211447120-.pdf>. Acesso em: 28 dez. 2011.

FALCÃO, T. Bolsa-Família, mais que transferência de renda. Disponível em: <http://www. mds.gov.br/saladeimprensa/artigos/>. Acesso em: 28 dez. 2011.

FONTES, V. O Brasil e o capital-imperialismo: teoria e história. 2. ed. Rio de Janeiro: EPSJV/Editora UFRJ, 2010.

FURTADO, C. O mito do desenvolvimento econômico. 2. ed. Rio de Janeiro: Paz e Terra, 1974.

GONÇALVES, R. Governo Lula e o nacional-desenvolvimentismo às avessas. Disponível em: <http://www.ie.ufrj.br/hpp/intranet/pdfs/texto_nacional_desenvolvimentismo_as_avessas_14_09_11_pdf.pdf>. Acesso em: 29 mar. 2012 
HARVEY, D. Condição pós-moderna: uma pesquisa sobre as origens da mudança cultural. 4. ed. São Paulo: Loyola, 1994.

O novo imperialismo. São Paulo: Loyola, 2004.

IAMAMOTO, M. V. A questão social no capitalismo. Temporalis, revista da Associação Brasileira de Ensino e Pesquisa em Serviço Social, Brasília, ano 2, n. 3, jan./jul. 2001.

IBGE. Síntese de indicadores sociais 2010. Disponível em: <www.ibge.gov.br>. Acesso em: 23 ago. 2011.

Em 2010, PIB varia 7,5\% e fica em R\$ 3,675 trilhões. Comunicação Social, 3 mar. 2011. Disponível em: <http://www.ibge.gov.br/home/presidencia/noticias/noticia_visualiza. php?id_noticia $=1830 \& i d$ pagina $=1 \&$ titulo=Em-2010,-PIB-varia-7,5\%-e-fica-em-R $\$-3,675$ -trilhoes>. Acesso em: 28 dez. 2011.

IPEA. Desigualdade e pobreza no Brasil metropolitano durante a crise internacional: primeiros resultados. Comunicação da Presidência n. 25, 4 ago. 2009. Disponível em: <www. ipea.gov.br>. Acesso em: 28 dez. 2011.

- Gastos com a política social: alavanca para o crescimento com distribuição de renda. Comunicados do Ipea, n. 75, fev. 2011a. Disponível em: <www.ipea.gov.br>. Acesso em: 28 dez. 2011.

. Natureza e dinâmica das mudanças recentes na renda e na estrutura ocupacional brasileiras. Comunicados do Ipea, n. 104, ago. 2011b. Disponível em: <www.ipea.gov.br>. Acesso em: 28 dez. 2011.

- Evolução da parcela do rendimento do trabalho durante a recente estabilidade monetária. Comunicados do Ipea, n. 134, fev. 2012. Disponível em: <www.ipea.gov.br>. Acesso em: 29 mar. 2012.

LEHER, R. Crise do capital e questão social. Revista Estudos do Trabalho, Marília, ano III, n. 6, 2010. Disponível em: http://www.estudosdotrabalho.org>. Acesso em:

MARX, K. O capital: crítica da economia política. 20. ed. Trad. de Reginaldo Sant'Anna. Rio de Janeiro: Civilização Brasileira, 2002a. Livro I, v. I.

O capital: crítica da economia política. 18. ed. Trad. de Reginaldo Sant'Anna. Rio de Janeiro: Civilização Brasileira, 2002b. Livro I, v. II.

MAURIEL, A. P. O. Combate à pobreza e desenvolvimento humano: impasses teóricos na construção da política social na atualidade. Tese (Doutorado) - IFCH/Unicamp, Campinas, 2008 .

MDS/Subsecretaria de Planejamento e Orçamento/Coordenação Geral de Planejamento e Avaliação. Financiamento da Assistência Social no Brasil. Nota Técnica, dez. 2010. 
MENDONÇA, L. J. V. P. de. Políticas econômicas e sociais na América Latina. Temporalis, revista da Associação Brasileira de Ensino e Pesquisa em Serviço Social. Temas contemporâneos e Serviço Social: crise do capital, trabalho, assistência social e formação profissional. Brasília, ano 1, v. 1 p. 11-30, jul./dez. 2010.

NETTO, J. P. Crise do socialismo e ofensiva neoliberal. Questões da Nossa Época, São Paulo, n. 20, 2. ed., 1995.

POCHMANN, M. Desenvolvimento e perspectivas novas para o Brasil. São Paulo: Cortez, 2010.

SALLUM JR., B. Desenvolvimentismos: o velho e o novo. Disponível em: <www.eagora. org.br/arquivo/desenvolvimentismos-o-velho-e-o-novo/P1>. Acesso em: fev. 2009.

SEN, Amartya. Desenvolvimento como liberdade. São Paulo: Companhia das Letras, 2000.

SICSÚ, J. Planejamento estratégico do desenvolvimento e as políticas macroeconômicas. Texto para Discussão, Brasília, Ipea, n. 1.346, 2008. Disponível em: <www.ipea.gov.br>. Acesso em: 29 mar. 2012.

SILVA, S. S. S. Entre a expansão do capital e a proteção ao trabalho: contradições da assistência social brasileira no governo neodesenvolvimentista. Tese (Doutorado) - UFPE, Recife, abr. 2012.

et al. Reestruturação produtiva e hipertrofiação da assistência social: a ofensiva do capital no Brasil. Temporalis, revista da Associação Brasileira de Ensino e Pesquisa em Serviço Social. Temas contemporâneos e serviço social: crise do capital, trabalho, assistência social e formação profissional. Brasília, ano 1, v. 1, jul./dez. 2010.

SOARES, M. A. T. Trabalho informal: da funcionalidade à subsunção ao capital. Vitória da Conquista: Edições Uesb, 2008. 